\title{
Knowledge, Attitudes, and Perception of Parents toward Dental Treatment of Children during the COVID-19 Outbreak
}

\author{
Poonam Sharma ${ }^{1}$, Preeti Dhawan ${ }^{2}$, Sumeet Rajpal ${ }^{3}$, Anu Bhat ${ }^{4}$
}

\begin{abstract}
This study aimed to evaluate the knowledge of parents regarding the coronavirus outbreak and to assess the change in attitude and perception toward dental treatment during the coronavirus (COVID-19) pandemic. A structured questionnaire (on google format) containing 13 questions was used, and each question had 2 or 3 possible answers. The parents/guardians of children (aged 3-14 years) who were school-going were eligible to participate in this study. A total of 800 parents/guardians were interviewed on google reporting format from June to December 2020. A simple random sampling technique was used to select 800 parents/guardians of children, aged 3-14 years, studying in different schools in Chandigarh. According to the survey, a total of $86 \%$ of respondents said that they paid high attention to COVID-19 and explained it to their children; $97 \%$ reported that they emphasized the importance of hand hygiene and sanitation during the outbreak; $72 \%$ admitted that the outbreak has made them more conscious of the importance of maintaining good oral health and hygiene, to avoid visiting the dentist and $84 \%$ felt that the routine dental check-ups and appointments should be avoided during the COVID-19 outbreak; almost half of the respondents (47\%) thought that the dental environment was a potential source of infection to their kids; $37 \%$ felt getting treatment at a dental setup may expose their child to risks of COVID-19; $71 \%$ said they would take their child to a dental department if he/she had a severe toothache. Approximately $46 \%$ of the respondents expressed confidence about the preventive measures taken in the dental department to ensure safe treatment for their children. In conclusion, all respondents were concerned about COVID-19 and most of them had talked about it with their children often. In addition, a considerable percentage of them showed apprehensions about the preventive measures being taken at the dental operatory and thought that the dental environment could be more dangerous than other environments.

Keywords: Coronavirus infections, COVID-19, Pandemic.

International Journal of Clinical Pediatric Dentistry (2021): 10.5005/jp-journals-10005-2041
\end{abstract}

\section{INTRODUCTION}

A novel human coronavirus disease-2019 coined as "COVID-19" became a public health emergency of international concern on January 31, 2020, and was later declared a pandemic on March 11, 2020. Given the widespread transmission of CoV-19, healthcare providers are at an increased risk of contracting the infection and becoming potential carriers of the disease. ${ }^{1}$

The transmission of COVID-19 in dental settings occurs through four major routes; directly through the respiratory secretions, saliva, blood, and indirectly by contact with contaminated surfaces and/or instruments such as dental chairs, their handles, the spittoon, and dental instruments; inhalation of suspended airborne viruses; and through the droplets or aerosols. ${ }^{1}$ According to Occupational Safety and Health Administration (OSHA), dental healthcare providers are in the high exposure risk category as they work in close proximity to the patient's oral cavity. ${ }^{2}$ Also, the dental procedures involve the use of rotary instruments which generate aerosols. Research has shown that coronaviruses can remain on metal, glass, and plastic surfaces for several days. Therefore, dental clinics can easily serve as venues for effectively spreading the cross-infection among patients and the dental team. ${ }^{2,3}$

Owing to the long incubation period (2-14 days), and the fact that children can be asymptomatic or present with mild, non-specific symptoms, all child patients should be considered as potential carriers of SARS-CoV-2 unless proved otherwise. ${ }^{4}$ Children are among the vulnerable groups who can easily contract the infection owing to their low immunity. Hence, the concern of the parents toward their exposure to a susceptible dental environment is well justified. Parents are the primary caregivers and their knowledge of the corona outbreak will definitely affect
${ }^{1-4}$ Department of Paedodontics and Preventive Dentistry, BRS Dental College, Sultanpur, Barwala, Panchkula, Haryana, India

Corresponding Author: Poonam Sharma, Department of Paedodontics and Preventive Dentistry, BRS Dental College, Sultanpur, Barwala, Panchkula, Haryana, India, Phone: +91 7206276456, e-mail: moon1737@gmail.com

How to cite this article: Sharma P, Dhawan P, Rajpal S, et al. Knowledge, Attitudes and Perception of Parents toward Dental Treatment of Children during the COVID-19 Outbreak. Int J Clin Pediatr Dent 2021;14(5):693-699.

Source of support: Nil

Conflict of interest: None

their perception toward dental treatment given to their children. At times, dental treatment is deferred because parents do not want their children to suffer the effects of possible procedural risks and may even refuse the treatment. Conceding a treatment can further potentiate the consequence of a disease..$^{5,6}$

Although the clinical manifestations of COVID-19 in children are reported to be less severe than those of adult patients, young children, and particularly infants, remain vulnerable to infection and pose a significant transmission risk. ${ }^{7}$ Dental teams must keep themselves abreast with the current understanding of local, regional, and national guidelines in a climate of uncertainty and frequent change to optimize safety for dental care providers and patients. 8,9

The dental departments need to adopt strict measures like screening of the patients, providing only emergency treatment, 
restricting aerosol operation as much as possible, use of extensive protection, and thorough environmental disinfection by keeping surfaces clean and dry. However, it will still be a challenge to prevent the transmission from the asymptomatic cases in the dental arena. ${ }^{10}$ Dentists who treat children during this pandemic should enact universal infection control procedures to the highest standard and champion this behavior through their teams. ${ }^{11}$

Moreover, a positive parenting attitude during these times may create an altogether new environment toward oral health which may have a direct bearing on the child, inculcating values and developing habits like a healthy diet and oral hygiene maintenance.

A large volume of information being infiltrated through multimedia could lead to confusion, e.g., contamination risks during treatments, etc., so it is important to know if there are any misconceptions so that dental professionals can help improve the hospital measures as well as patient education. ${ }^{12}$ The present study thus, besides, assessing the knowledge of the parents toward the pandemic, also aims to gauge any misconception among the parents.

\section{Materials and Methods}

Between June and December 2020, about 800 parents/guardians of the school-going children of different schools of Chandigarh were interviewed using a google format, in a randomized manner. The parents/guardians of children between the age-group of 3 years and 14 years were included in the study.

Before the beginning of the study, the study design and objective (Section I) was explained to the parents/guardians and they were asked to sign/accept a statement of informed consent in Hindi or English (Section II) as per his/her preference.

After obtaining the consent, parents were invited to answer the questionnaire. The questionnaire was bilingual (i.e., English and Hindi) and the parent could choose from the two as per his/ her preference.

To ensure confidentiality and privacy, an individual's information or responses was concealed and not disclosed to any other individual or organization in any form.

\section{Questionnaire}

Section III consisted of questions recording the demographic details, name, age/sex of the child, the relation of the respondent to the child, and the educational level of the parent/guardian. Based on these demographic details, the knowledge and awareness of the respondents were determined. ${ }^{13}$ Following details were recorded as part of this section:

- Particulars of the reporting parent/guardian (name, age, relation w.r.t the child).

- The educational level of the parent/guardian.

- Name and age of the school-going child.

The study questionnaire (Section IV) contained 13 questions and was based on similar research. ${ }^{14}$ The questions were written in Hindi and English for ease of understanding. The questionnaire used is given below.

- Do you keep yourself abreast with the latest updates on COVID$19 ?$

- Doyou try to provide the relevant information regarding COVID19 to your kids?
- Do you emphasize the importance of hand hygiene and sanitation to your children?

- Is your child suffering from any dental illness at present?

- Have you ever visited any dentist in the past for your kid's treatment?

- Have you ever visited any dentist in the past 3 months (post corona outbreak) for your kid's treatment?

- Do you feel the dental OPD environment is a source of infection to your child?

- Would you take your child to a dentist if he/she gets a toothache?

- Do you feel getting treatment at a dental setup may expose your child to risks of COVID-19?

- What do you think your child could get infected from, in a dental OPD?

- If the dental OPD assures you of all the required protective measures during the treatment would you rely on the measures and undertake the treatment?

- Has the outbreak made you more conscious of the importance of maintaining good oral health and hygiene to avoid visiting the dentist?

- Do you feel that routine dental checkups and appointments should be avoided during the COVID-19 outbreak?

\section{Statistical Analysis}

The responses to the questionnaires thus collected, were pooled in accordance with the demographic and the perception category. Multiple comparisons were used to compare pooled questionnaire responses by age group, education level. ${ }^{15}$ Microsoft Excel was used for statistical analysis. Data thus collected were statistically evaluated to assess the knowledge, attitude, and perception of the respondents toward dental treatment during the outbreak.

\section{Results}

The basic data on the age of the respondents and school-going children, as well as the highest level of education, are shown in Figures 1 to 3.

The majority of the respondents were in the age-group of 30-40 years and were postgraduates in terms of education level. Among them, a large proportion had kept themselves updated

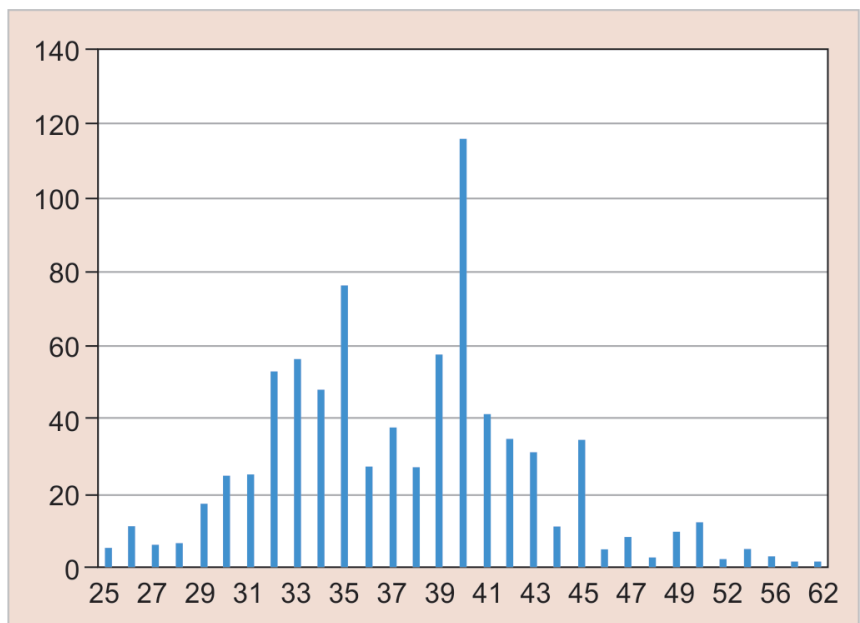

Fig. 1: Age of the respondent (years) 
with the latest information on COVID-19 and all had passed on the relevant information to their child/children. The higher proportion of respondents in the age group 20-30 and 40 years or above kept themselves updated regarding the COVID-19 and explained it to their children. Meanwhile, this response was higher with respondents having postgraduate education when compared with the respondents with undergraduate or lower education levels (Figs 4 to 8 ).

All the respondents were concerned about COVID-19, and almost all of them emphasized the importance of hand hygiene and sanitation to their children. The greater part of the respondents admitted that the outbreak has made them more conscious of the importance of maintaining good oral health and hygiene.

Almost half of the respondents thought that the environment of the dental department was dangerous. Among them, the respondents aged $30-40$ years were of the opinion that the dental department environment was more dangerous. This was significant when compared with the respondents aged 20-29 years. The proportion of this response was higher with respondents having postgraduate education compared with the respondents with undergraduate education.

Most respondents were not sure if their children could be easily infected with the virus while receiving dental treatment while the others were confident that dental treatment could infect their children while a few thought that the risk was similar to that of other public places or believed there was no significant risk.

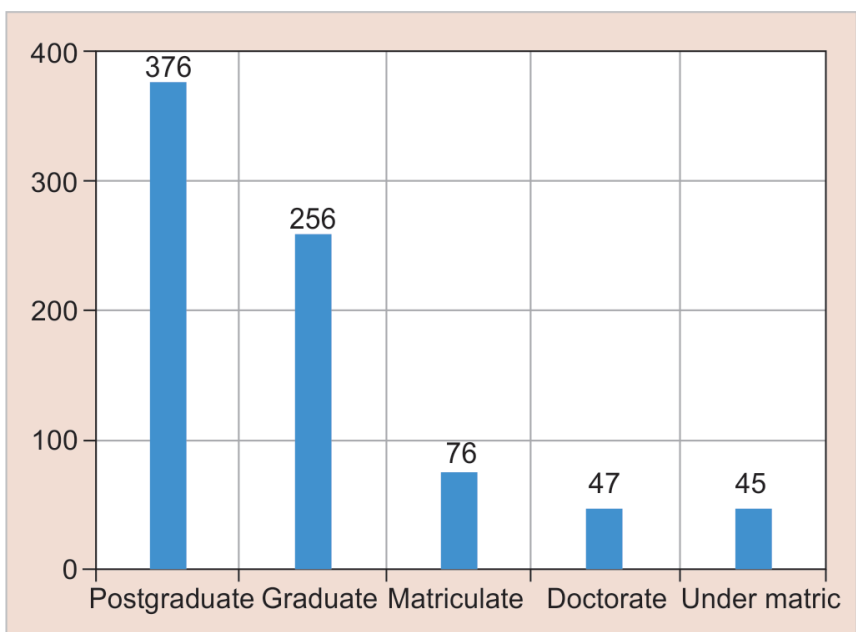

Fig. 2: Educational level of respondent

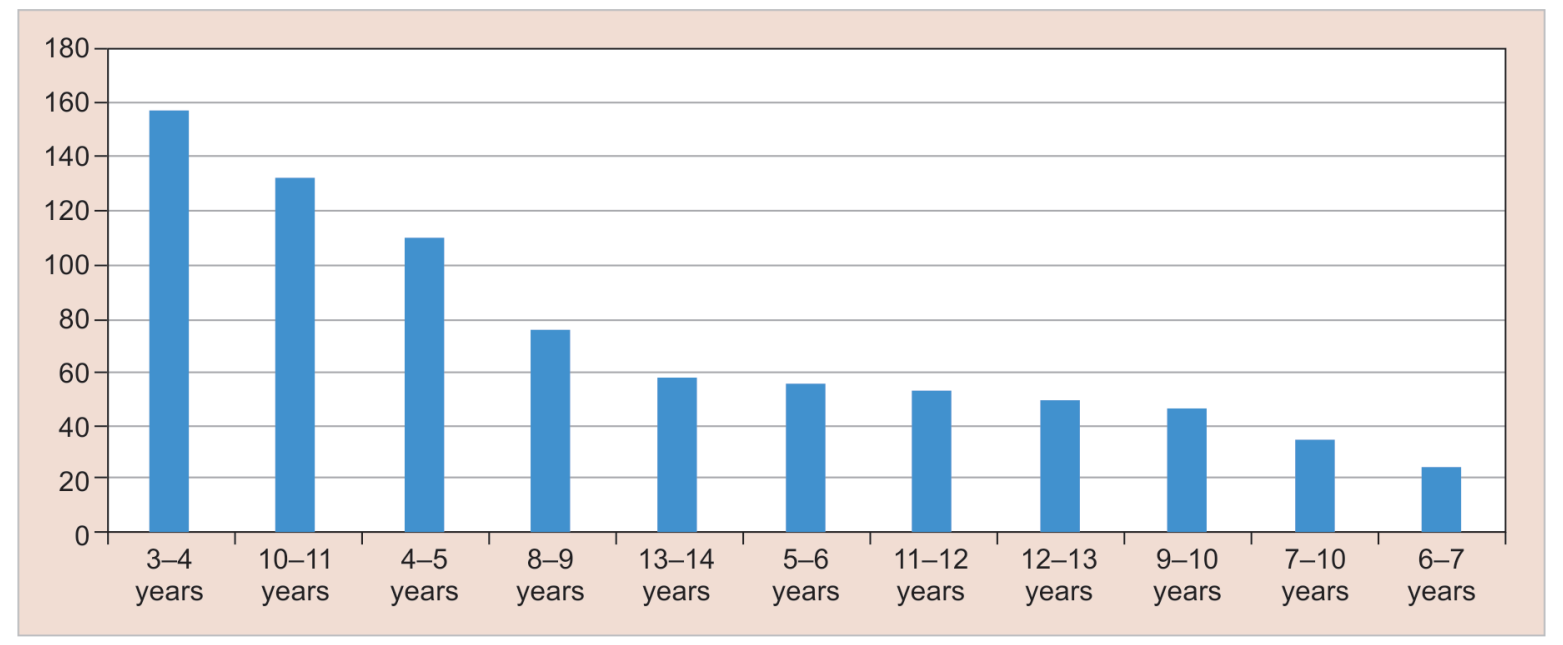

Fig. 3: Age of the school-going child

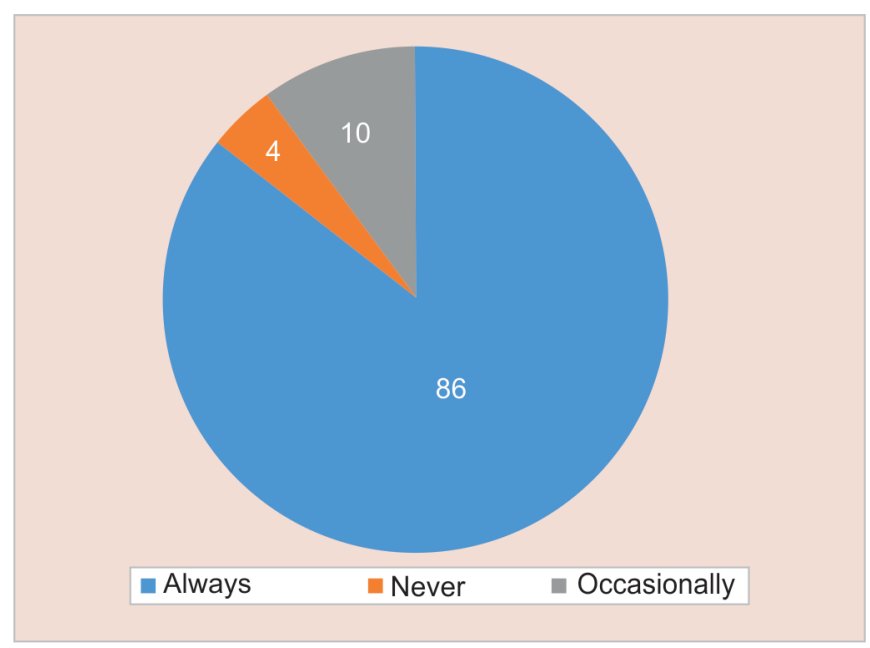

Fig.4: Do you keep yourself abreast with the latest updates on COVID-19?

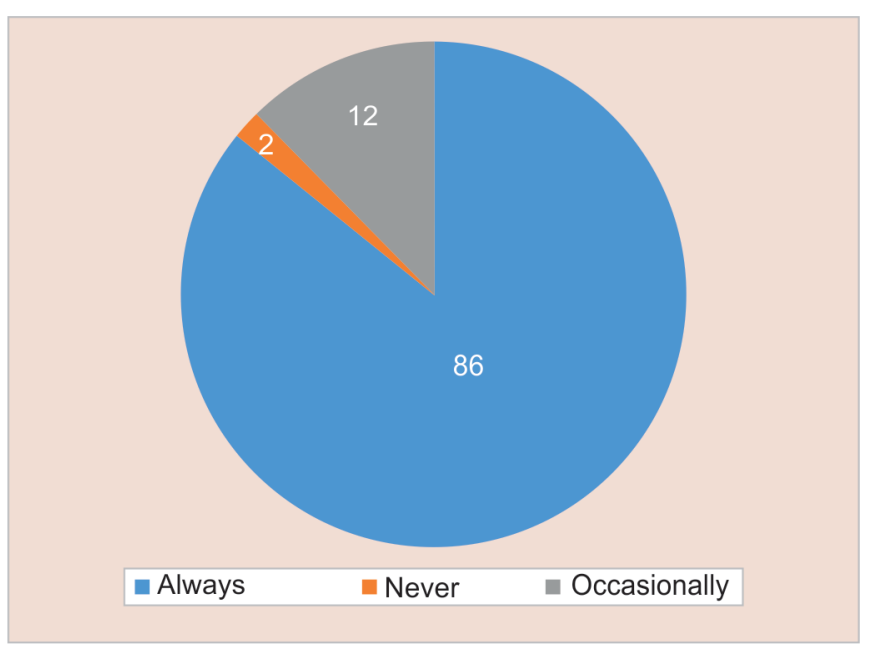

Fig. 5: Do you try to provide the relevant information regarding COVID-19 to your kids? 


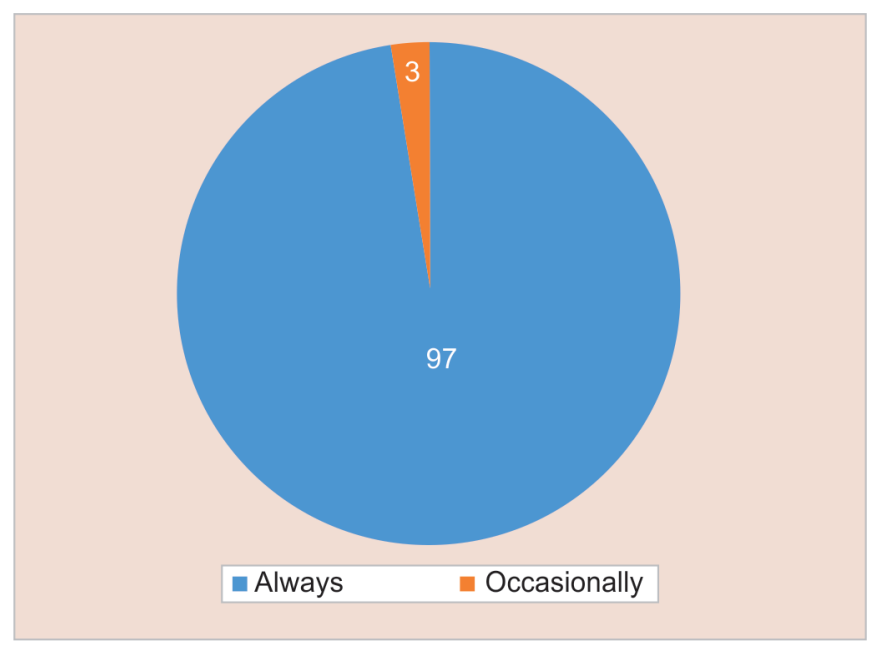

Fig. 6: Do you emphasize the importance of hand hygiene and sanitation to your children?

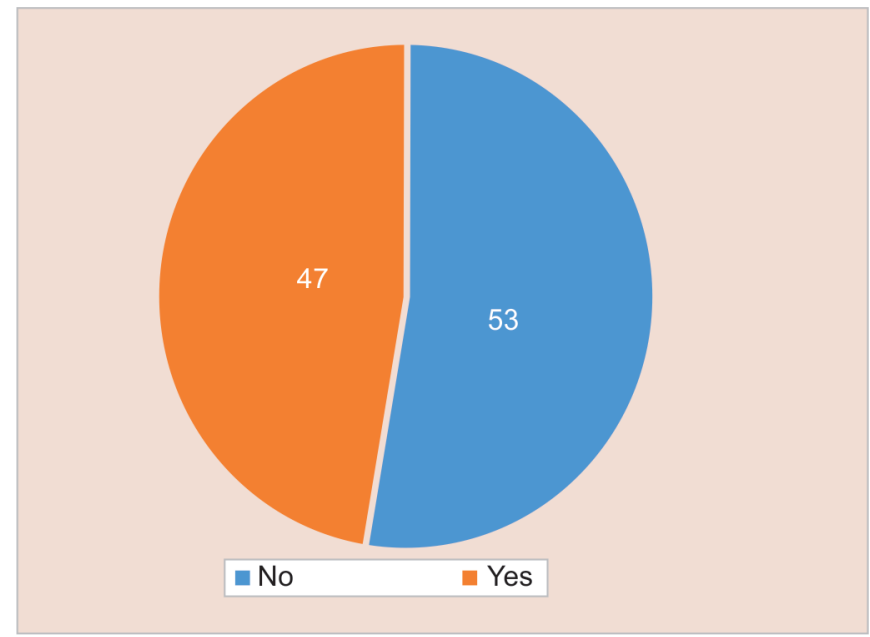

Fig. 8: Do you feel the dental OPD/clinic environment is a source of infection to your child?

Among the respondents, most thought that the entire dental setup was the main cause of infection, while others had varied opinions on the mode of transmission of infection in the dental OPD while one-fourth of them thought that the dental setup was not infective at all. The proportion of respondents aged 20-30 and 30-40 years who thought their children could be easily infected during dental treatment was higher, compared with those aged 40 years or above (Figs 9 to 12).

About three-fourth of the respondents would take their child to the dentist during the outbreak if he/she had a severe toothache; the rest responded negatively. Among them, compared with the parents aged 30-40 years, parents aged 20-29 years were more willing to take their children to a dental department or dentist for teeth-related pain. Meanwhile, parents with an undergraduate education were less willing, while those with a postgraduate education were relatively more willing. Most of the parents believed that routine dental visits should be avoided during the outbreak, while a smaller proportion was in favor of routine dental check-ups and appointments during this time.

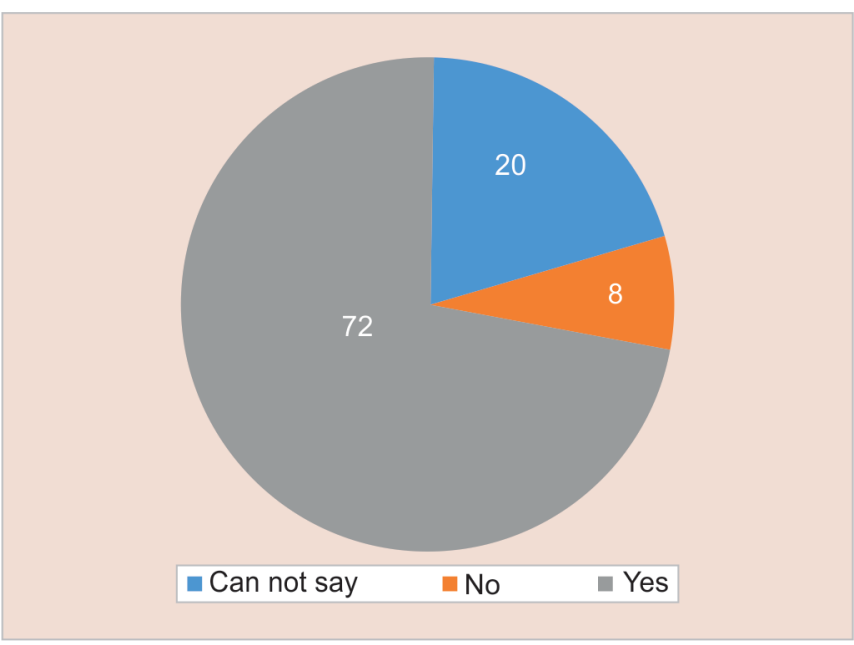

Fig. 7: Has the outbreak made you more conscious of the importance of maintaining good oral health and hygiene to avoid visiting the dentist for your child?

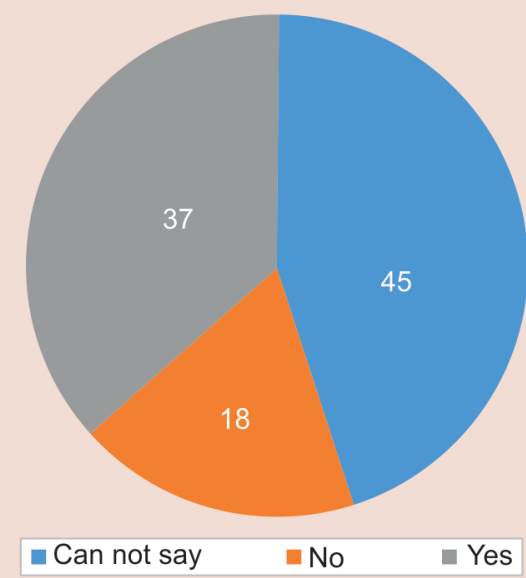

Fig. 9: Do you feel getting treatment at a dental setup may expose your child to risks of COVID-19?

The majority of the respondents reported that their children were not suffering from any dental ailment at the time of the study and almost all respondents reported that they did not visit any dentist during the last 3 months past the corona outbreak.

Three-fourth of the respondents denied taking their kids to the dentist ever in the past. Most of the respondents were still uncertain to undertake dental treatment for their children even if they were assured that the department had taken protective measures. ${ }^{16,17} \mathrm{An}$ almost equal number of respondents mentioned that they would visit the dental clinic in case the protective measures were assured.

\section{Discussion}

The corona pandemic has invariably affected every aspect of our lives. Parents play a pivotal role in children's oral healthcare and their knowledge and attitude have a direct bearing on the perception of the dental treatment for their children. ${ }^{18}$

The timeliness and efficient reporting of the multimedia has been instrumental in keeping the public updated with the latest 


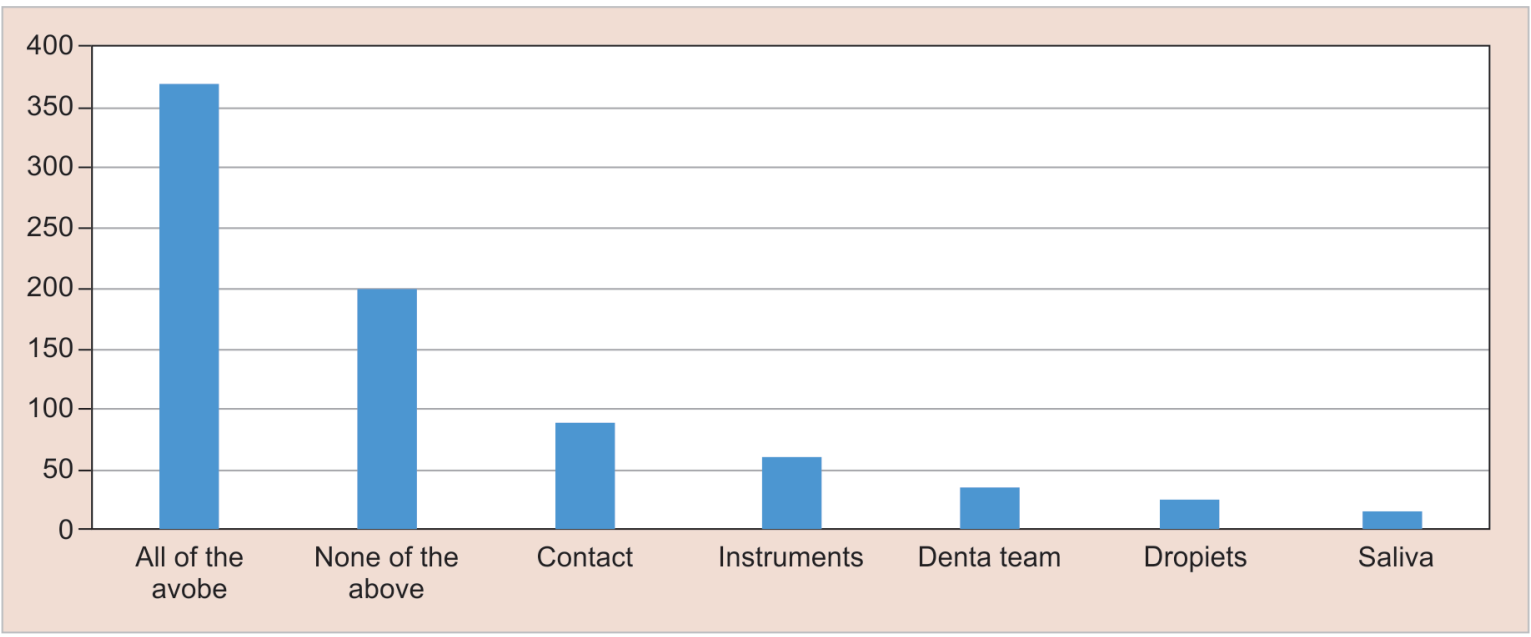

Fig. 10: What do you think your child could get infected from, in a dental OPD?

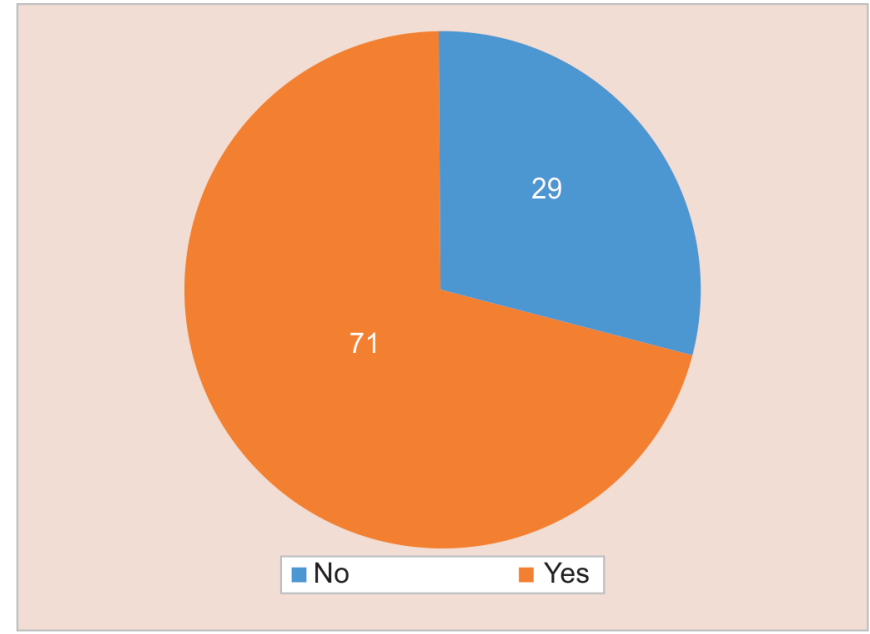

Fig. 11: Would you take your child to a dentist if he/she gets a toothache?

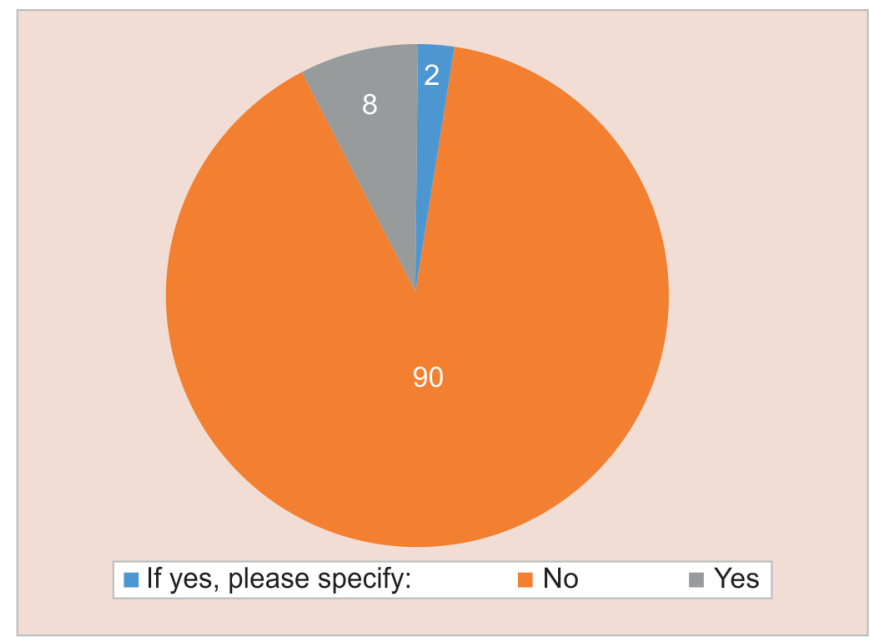

Fig. 13: Is your child suffering from any dental illness at present

during the pandemic. This was very well reflected in the study as the majority of respondents were abreast with the news and information on the corona pandemic and almost all of them

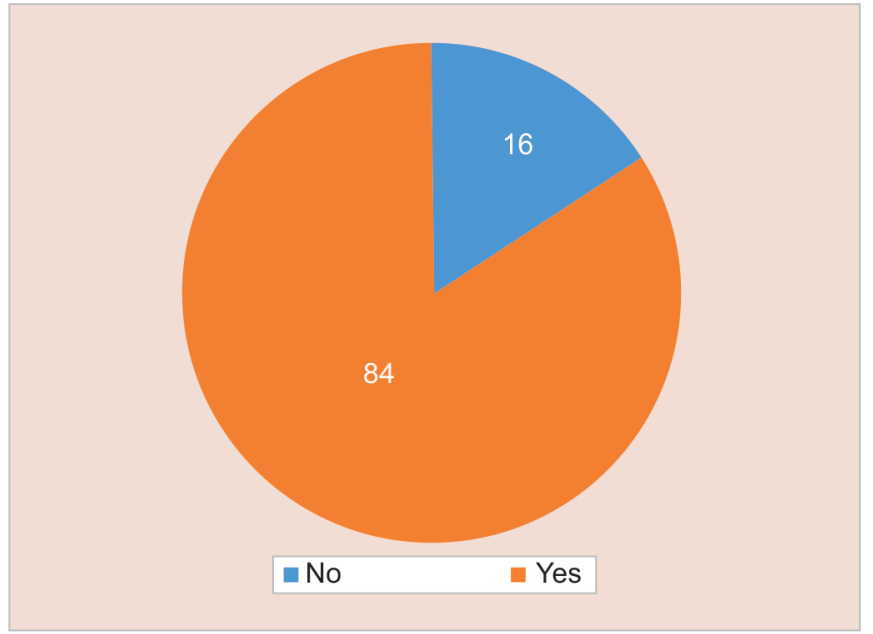

Fig. 12: Do you feel that routine dental check-ups and appointments should be avoided during the COVID-19 outbreak?

tried percolating the required relevant information to their kids (Figs 13 to 16 ).

Most of the respondents were postgraduates or graduates and their educational levels reflected in their knowledge about the outbreak and the vulnerability of their children getting infected.${ }^{19}$ However, it was surprising that in an urban population like Chandigarh, there were a fraction of respondents who never had any access to these updates and thus never passed on the same to their children (2-4\%). The health authorities need to strengthen their focus on these areas.

Most of the parents had their children in the age group between 3 years and 10 years; which is a significant age when the parent's attitude and perception has a direct bearing on the child's dental health.

A large number of respondents reported that they emphasized the importance of hand hygiene and sanitation to their children. The awareness on sanitation will go a long way in protecting the children not only from COVID infection but the habit thus inculcated, will prevent the transmission of other contagious diseases, considering the children as the most vulnerable group owing to the low immunity. 


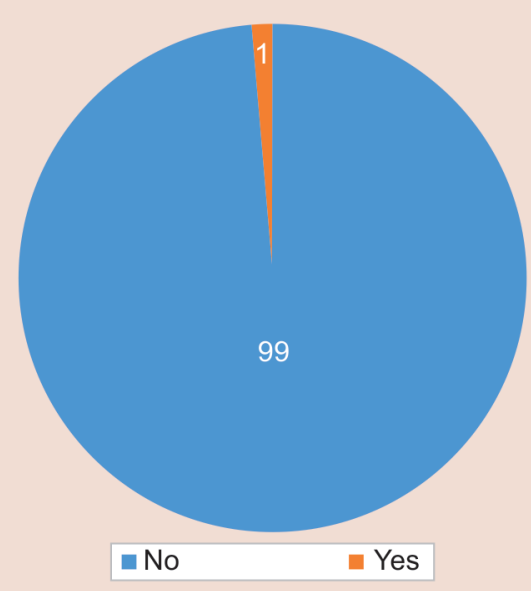

Fig. 14: Have you ever visited any dentist in the past 3 months (post corona outbreak) for your kid's treatment

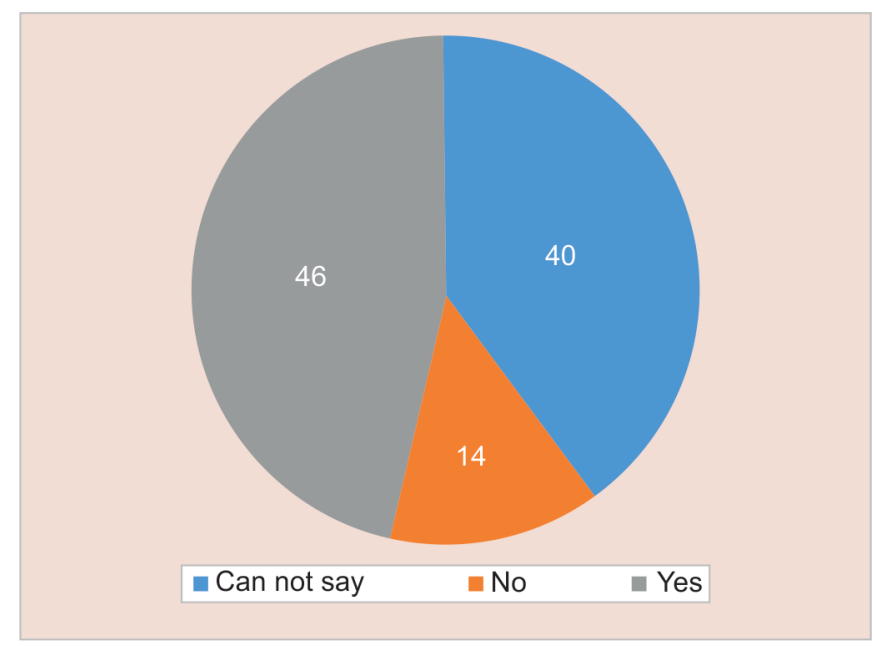

Fig. 16: If the dental OPD assures you of all the required protective measures during the treatment would you rely on the measures and undertake the treatment?

The high literacy level and concern of the respondents toward the children's oral health results in a low prevalence of oral disease in the urban population like Chandigarh, as reflected in the majority of responses with no significant/acute dental illness during the pandemic.

Three-fourth of the respondents had not visited the dentist in the past for any dental ailment. This can be speculated as a lack of awareness regarding early dental check-ups in children and the fact that the advocated advisory of regular dental visits has had a little effect even in the educated urban populations. The parents at large avoid visiting a dentist unless necessitated by an acute condition or otherwise. This calls for a concern regarding the importance of preventive oral health being emphasized among the masses at large. ${ }^{20,21}$

Though an appreciable number of parents were candid in taking their child to the dentist for a toothache yet $29 \%$ responded negatively. The attitude of the parents in avoiding the timely management of dental ailments may eventually potentiate the

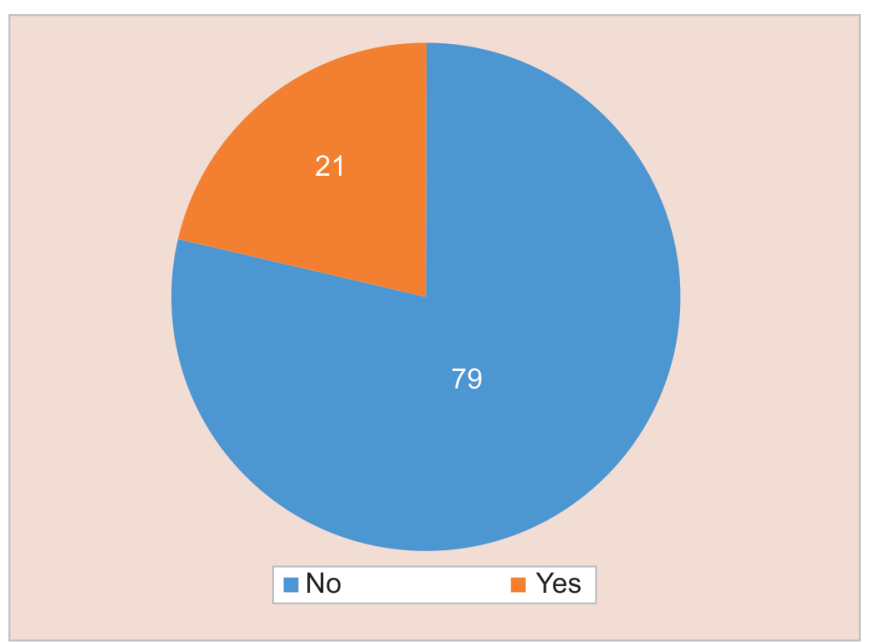

Fig. 15: Have you ever visited any dentist in the past for your kid's treatment?

problem, escalating not only the financial burden on parents but also the physiological and dental trauma to the children.

The good part reflected in the study was that the outbreak had made the parents more conscious of the importance of maintaining good oral health and hygiene to avoid visiting the dentist. This will definitely pave the way for promoting the preventive aspect in managing dental problems in pediatric patients.

\section{Conclusion}

Although all parents were concerned about COVID-19, and most of them had talked about it with their children often, a considerable percentage of them would not take their children to the dental department even if their children had severe dental pain and were divided in their opinion whether the dental environment could be more dangerous than other environments.

Though the respondents were aware of the corona pandemic in general, however, they had limited knowledge regarding the role of the dental environment in the spread of the infection. ${ }^{22,23}$ The perception of the parents toward the risk of visiting a dentist could be justified on the basis that they had little confidence in the preventive measures undertaken during the outbreak. When the risk is unknown people tend to avoid emergency dental situations too. ${ }^{24,25}$ This was quite alarming as emergency situations, if unnoticed or unattended, would result in adverse health consequences. Diligent efforts should be directed toward informing the public regarding the strict measures undertaken to avoid contamination in dental offices and that dental cases can be treated with lower risk. ${ }^{26,27}$

The sample size of 800 may not fully reflect the perception of society at large. Moreover, this study was conducted during the outbreak of COVID-19. The threatened environment and the changing responses against COVID may have impacted the responses. ${ }^{28-30}$ Complex challenges in the virtual study cannot be ruled out. Though the study represents a temporarily small sample, it still has research significance.

\section{References}

1. Mallineni SK, Innes NP, Raggio DP, et al. Coronavirus disease (COVID-19): characteristics in children and considerations for dentists providing their care. 2020(3):245-250. DOI: 10.1111/ipd.12653. 
2. Ayatollahi J, Ayatollahi F, Ardekani AM, et al. Occupational hazards to dental staff. Dent Res J 2012;9(1):2. DOI: 10.4103/1735-3327. 92919.

3. Bhanushali P, Katge F, Deshpande S, et al. COVID-19: Changing trends and its impact on future of dentistry. Int J Dentis 2020;2020:8817424. DOI: 10.1155/2020/8817424.

4. Ren $Y F$, Rasubala $L$, Malmstrom $H$, et al. Dental care and oral health under the clouds of COVID-19. JDR Clin Translat Res 2020;5(3):202-210. DOI: $10.1177 / 2380084420924385$.

5. Moffat RC, Yentes CT, Crookston BT, et al. Patient perceptions about professional dental services during the COVID-19 pandemic. JDR Clin Translat Res 2020;6(1):15-23. DOI: 10.1177/2380084420969116.

6. Samuel SR, Kuduruthullah S, Khair AM, et al. Dental pain, parental SARS-Cov2 fear and distress on quality of life of 2-6-year-old children during COVID-19. Int J Paediat Dentis 2021;31(3):436-441. DOI: 10.1111/ ipd.12757.

7. Ji LN, Chao S, Wang YJ, et al. Clinical features of pediatric patients with COVID-19: a report of two family cluster cases. World J Pediat 2020(3):1-4. DOI: 10.1007/s12519-020-00356-2.

8. Harrel SK, Molinari J. Aerosols and splatter in dentistry: a brief review of the literature and infection control implications. J Am Dent Assoc 2004;135(4):429-437. DOI: 10.14219/jada.archive.2004.0207.

9. Morawska L, Milton DK. It is time to address airborne transmission of coronavirus disease 2019 (COVID-19). Clin Infect Dis 2020;71(9):23112313. DOI: $10.1093 / \mathrm{cid} / \mathrm{ciaa939}$.

10. Peng $X, X u X, L i$, et al. Transmission routes of 2019-nCoV and controls in dental practice. Int J Oral Sci 2020;12(1):1-6. DOI: 10.1038/s41368020-0075-9.

11. Brondani M, Donnelly L. The HIV and SARS-CoV-2 parallel in dentistry from the perspectives of the oral health care team. JDR Clin Translat Res 2021;6(1):40-46. DOI: 10.1177/2380084420961089.

12. Coulthard P. Dentistry and coronavirus (COVID-19)-moral decisionmaking. Br Dent J 2020;228(7):503-505. DOI: 10.1038/s41415-0201482-1.

13. Saleem SM. Modified Kuppuswamy socioeconomic scale updated for the year 2020. Indian J Foren Community Med 2020;7(1):1-3. DOI: $10.18231 / j . i j f c m .2020 .001$.

14. Sun J, Xu Y, Qu Q, et al. Knowledge of and attitudes toward COVID-19 among parents of child dental patients during the outbreak. Brazi Oral Res 2020. 34. DOI: 10.1590/1807-3107bor-2020.vol34.0066.

15. Campagnaro R, de Oliveira Collet G, de Andrade MP, et al. COVID-19 pandemic and pediatric dentistry: fear, eating habits and parent's oral health perceptions. Child Youth Ser Rev 2020;118:105469. DOI: 10.1016/j.childyouth.2020.105469.

16. Brondani M, Cua D, Maragha T, et al. A Pan-Canadian narrative review on the protocols for reopening dental services during the COVID-19 pandemic. BMC Oral Health 2020;20(1):1-3. DOI: 10.1186/s12903-02001340-y.

17. Lipson ME, Deardon R, Switzer NJ, et al. Practice and attitudes regarding double gloving among staff surgeons and surgical trainees. Can J Surg 2018;61(4):244. DOI: 10.1503/cjs.013616.

18. Brondani M, Donnelly L. The HIV and SARS-CoV-2 parallel in dentistry from the perspectives of the oral health care team. JDR Clin Translat Res 2020;34:e066.

19. Nicola M, Alsafi Z, Sohrabi C, et al. The socio-economic implications of the coronavirus and COVID-19 pandemic: a review. Int J Surg 2020;78:185-193. DOI: 10.1016/j.ijsu.2020.04.018.

20. Fan W, Su Z, Bin Y, et al. A new coronavirus associated with human respiratory disease in China. Nature 2020;579(7798):265-269. DOI: 10.1038/s41586-020-2008-3.

21. Liu W, Zhang QI, Chen J, et al. Detection of Covid-19 in children in early January 2020 in Wuhan, China. N Eng J Med 2020;382(14):1370-1371. DOI: 10.1056/NEJMc2003717.

22. Setti L, Passarini F, De Gennaro G, et al. Airborne transmission route of COVID-19: why 2 meters/6 feet of inter-personal distance could not be enough. Int J Environ Res Public Health 2020;17(8):2932. DOI: 10.3390/ijerph17082932.

23. Ahmed MA, Jouhar R, Ahmed N, et al. Fear and practice modifications among dentists to combat novel coronavirus disease (COVID-19) outbreak. Int J Environ Res Public Health 2020;17(8):2821. DOI: 10.3390/ijerph17082821.

24. Guo H, Zhou Y, LiuX, et al. The impact of the COVID-19 epidemic on the utilization of emergency dental services. J Dent Sci 2020;15(4):564567. DOI: 10.1016/j.jds.2020.02.002.

25. Kranz AM, Gahlon G, Dick AW, et al. Characteristics of US adults delaying dental care due to the COVID-19 pandemic. JDR Clin Translat Res 2021;6(1):8-14. DOI: 10.1177/2380084420962778.

26. Meng L, Hua F, Bian Z. Coronavirus disease 2019 (COVID-19): emerging and future challenges for dental and oral medicine. J Dent Res 2020;99(5):481-487. DOI: 10.1177/0022034520914246.

27. Emami E. COVID-19: perspective of a dean of dentistry. JDR Clin Translat Res 2020;5(3):211-213. DOI: 10.1177/2380084420929284.

28. Wu Z, McGoogan JM. Characteristics of and important lessons from the coronavirus disease 2019 (COVID-19) outbreak in China: summary of a report of 72314 cases from the Chinese center for disease control and prevention. JAMA 2020;323(13):1239-1242. DOI: 10.1001/ jama.2020.2648.

29. American Dental Association. ADA interim guidance for management of emergency and urgent dental care. 2020. 1. Updated April.

30. Bahramian H, Gharib B, Baghalian A. COVID-19 considerations in pediatric dentistry. JDR Clin Translat Res 2020;5(4):307-311. DOI: $10.1177 / 2380084420941503$. 